\title{
EUGENICS TODAY: AN INTERDISCIPLINARY TEACHING FOR HIGHER EDUCATION
}

\author{
Andreas-Evangelia Spathi, Afroditi Kalemi, Athina Kontostavlaki, Evridiki Efstathiou, \\ \& Lefkothea-Vasiliki Andreou \\ Department of Biological Applications and Technology, University of Ioannina (Greece)
}

\begin{abstract}
Eugenics involves the application of scientific practice to promote selective breeding in the human population. Notably, although considered unethical and outdated many science papers on the topic are still heavily cited. In the present study, a lesson plan has been produced for an English for Academic Purposes/English for Scientific Purposes (EAP/EScP) course in a Biology Department in Higher Education, to be held on the occasion of the International Holocaust Remembrance Day (27th of January). In a two-fold approach, students are first introduced to the history and background of the eugenics movement and then presented with current relevant bioethics issues. In the first part, students watch video footage, discuss on archive material and are subsequently asked to produce posters and audiovisual material on seminal eugenics cases. In the second part, students are randomly assigned to one of two groups and a debate is held on the topic of embryo designing and the possible risk of a modern eugenics rise. The activities chosen for this lesson promote interdisciplinary education, student-centered practices and active learning. Importantly, the topic lends itself to the coupling of science communication and humanities, also referred to as biomedical humanities. Post-lesson responses to a questionnaire reveal that although initially largely unaware of the issues discussed here, the students form clear views on the importance of historical memory and bioethics education.
\end{abstract}

Keywords: Eugenics, higher education, science communication, biomedical humanities, interdisciplinary education.

\section{Introduction}

The term eugenics was coined by Francis Galton (Barnett, 2004), cousin of Charles Darwin, but the ideology dates as far back as in ancient Greece (Galton, 1998). It involves the attempt to regulate human procreation based on scientific findings from the field of genetics. Although nowadays these practices have been abandoned and are deemed unethical, paradoxically, several outdated science papers are still being cited (Cohen, 2017). In this paper, in the context of an English for Academic Purposes/English for Scientific Purposes (EAP/EScP) course, we introduce students of a Biology Department in Higher Education to the historical background of some seminal eugenics cases. We also discuss cutting-edge research techniques, such as CRISP (Clustered Regularly Interspaced Short Palindromic Repeats) (Ormond et al., 2017) and current concerns that the unmonitored application of this technology may spark a eugenics movement revival (Knoepfler, 2015; Verlinky, 2005). Importantly, we ask students to engage with the topic in activities that promote interdisciplinarity (Moss, Osborn, \& Kaufman, 2008), critical thinking (Chowning, Griswold, Kovarik, \& Collins, 2012) and active learning (Freeman et al., 2014). Furthermore, the lesson plan boosts visual literacy and technology literacy via the use of Web 2.0 tools and relevant audio-visual material (Andreou, 2019).

\section{Methodology}

Subject area: Biology, English for Academic Purposes/English for Scientific Purposes (EAP/EScP), Topic: Eugenics, International Holocaust Remembrance Day, Age group: 18+, Duration: 2 teaching hours. 


\subsection{Purpose}

On the occasion of the International Holocaust Remembrance Day ( $27^{\text {th }}$ of January) a lesson plan is devised to educate science students regarding the practice of eugenics. The purpose of the educational micro-scenario is to inform them about the eugenics movement, past applications and possible future implications of recent science achievements such as embryo designing.

\subsection{Educational aims}

Through this teaching approach we aim to: 1 . Inform students about the eugenics movement and possible present and future applications and risks, 2. Familiarize students with interdisciplinary teaching (e.g. Biology, EAP/EScP, History and Bioethics), 3. Highlight the ethical implications of controversial science applications and discuss bioethics, 4. Encourage students to adopt a responsible attitude towards controversial scientific practices, 5. Help students improve their collaborative skills, 6. Practice debating on a subject and promote critical thinking, 7. Encourage artistic expression and 8. Promote students' technology and visual literacy via the use of Web 2.0 tools and relevant audiovisual material.

\subsection{Materials}

1. Video projector, 2. IT classroom with internet connection and 3. Student Smartphones / Tablets / Laptops

\subsection{Procedure}

The present micro-scenario comprises of Information Technology (IT)-enhanced micro-activities that involve issues on eugenics and bioethics. The micro-activities span over two teaching hours. In the first hour, we provide an introduction on eugenics and the background of the movement. In the second hour, we focus on the bioethical implications of recent science advancements in Biology.

2.4.1. $1^{\text {st }}$ phase (duration: 45 minutes). $1^{\text {st }}$ micro-activity (duration: 15 minutes). Introduction to eugenics using a teamwork activity.

1. Warmer: Students watch a short video by Cold Spring Harbor Laboratory on forced sterilization during the American eugenics movement (https://www.cshl.edu/dnalcmedia/forcedsterilization-during-the-american-eugenics-movement-james-watson/\#description). They then read an extract published online by Cambridge University Press on the Lebensborn breeding plan (https://www.cambridge.org/core/journals/central-european-history/article/lebensborn-and-theeugenics-policy-of-the-reichsfuhrerss/45858920D4BF64CAD2DC33A5D8DB8655) (Thompson, 1971). A discussion is held with a reference to selective breeding and bioethics.

2. Students are directed to the Auschwitz Museum website (http://auschwitz.org/en/) and to the Medical Experiments section. They are asked to identify representatives of the eugenics movement. We interact with the students and answer questions on the information collected.

3. Students are requested to produce as homework, in teams, a short video compilation on the Vyond online platform (https://www.vyond.com/). The videos should be featuring images, audio and text produced by the students on the topic of seminal eugenics cases.

$2^{\text {nd }}$ micro-activity (duration: 30 minutes). Poster activity.

1. Warmer: we introduce students to open source material and direct them to the WikiMedia Commons repository (https://commons.wikimedia.org/).

2. We instruct students to search for audiovisual material on eugenic practices that they may use for their posters.

3. Students produce their posters on the online app Glogster (https://edu.glogster.com/). They are instructed to use at least one feature of each of the following categories: audio, video, text, image.

2.4.2. $2^{\text {nd }}$ Phase: (duration: 40 minutes). $3^{\text {rd }}$ micro-activity (duration: 40 minutes). Debate on the topic of introducing CRISP technology to embryo genetic engineering (Ormond et al., 2017).

1. Warmer: We discuss the CRISP technology in connection to human genome editing. We distribute double-sided (YES; green, NO; red) cards to the students and we quickly hold a poll by asking them to vote whether they consider genetic modification of embryos ethical. A vote count takes place.

2. We project excerpts (6:08-12:36 \& 15:10-18:00) of Paul Knoepflers' TEDx talk "The ethical dilemma of designer babies" (Knoepfler, 2015). We ask students to read the transcript of the entire talk.

3. Regardless of their personal views, students are randomly assigned to two groups using the Random Integer Generator (https://www.random.org/). Team 1 is in favor of embryo genetic modification and Team 2 is against it.

4. Students are allowed a 10-min brainstorming session to prepare their arguments. 
5. The debate lasts about 10min, consisting of three sessions of arguments and counterarguments. The debate ends with a fresh vote count.

6 . In the remaining time, a plenary discussion is held on science communication. Students are encouraged to elaborate on means of communicating controversial biology topics to the general public.

2.4.3. Evaluation (duration: 5 minutes). Students were requested to complete an exit ticket before leaving class (https://code.org/learn). The exit ticket evaluation sheet comprised of three fields: "Today I learned:". "Today I experienced:", "Today I felt:"

\section{Discussion}

Feedback from the students shows that, although largely unaware of the issues discussed in the present lesson plan, they became increasingly interested in the topics and appreciated the importance of historical memory and bioethics education. Furthermore, when prompted to discuss the communication of controversial science topics, especially to a general, non-expert audience, they express their appreciation (Fischhoff \& Scheufele, 2013). Importantly, the topic of eugenics lends itself for interdisciplinary educational approaches, a combined approach of science and the humanities. This paper is thus in line with studies in the field of biomedical humanities (Fried, Madar, \& Donley, 2003).

\section{References}

Andreou, L.-V. (2019). Remembrance Day: A Micro-Scenario-Based Teaching of English as a Foreign Language Employing Micro-Activities in a Digital Environment. INTED2019 Proceedings. doi: 10.21125/inted.2019.1833

Barnett, R. (2004). Eugenics. The Lancet, 363(9422), 1742.

Chowning, J. T., Griswold, J. C., Kovarik, D. N., \& Collins, L. J. (2012). Fostering Critical Thinking, Reasoning, and Argumentation Skills through Bioethics Education. PLoS ONE, 7(5). doi: 10.1371/journal.pone.0036791

Cohen, A. (2017). Imbeciles: The Supreme Court, American eugenics, and the sterilization of Carrie Buck. NY, NY: Penguin Books.

Fischhoff, B., \& Scheufele, D. A. (2013). The science of science communication. Proceedings of the National Academy of Sciences, 110(Supplement_3), 14031-14032. doi: 10.1073/pnas.1312080110

Freeman, S., Eddy, S. L., Mcdonough, M., Smith, M. K., Okoroafor, N., Jordt, H., \& Wenderoth, M. P. (2014). Active learning increases student performance in science, engineering, and mathematics. Proceedings of the National Academy of Sciences, 111(23), 8410-8415. doi: 10.1073/pnas.1319030111

Fried, C., Madar, S., \& Donley, C. (2003). The biomedical humanities program: Merging humanities and science in a premedical curriculum at Hiram College. Academic Medicine, 78(10), 993-996.

Galton, D. J. (1998). Greek theories on eugenics. Journal of medical ethics, 24(4), 263-267.

Knoepfler, P. (2015). The ethical dilemma of designer babies. Retrieved March 13, 2020, from https://www.ted.com/talks/paul_knoepfler_the_ethical_dilemma_of_designer_babies\#t-925509

Moss, D. M., Osborn, T. A., \& Kaufman, D. (2008). Interdisciplinary éducation in the age of assessment. New York: Routledge.

Ormond, K. E., Mortlock, D. P., Scholes, D. T., Bombard, Y., Brody, L. C., Faucett, W. A., ... \& Musunuru, K. (2017). Human germline genome editing. The American Journal of Human Genetics, 101(2), 167-176. https://doi.org/10.1016/j.ajhg.2017.06.012

Thompson, L. V. (1971). Lebensborn and the Eugenics Policy of the Reichsführer-SS. Central European History, 4(1), 54-77. doi:10.1017/S0008938900000443

Verlinsky, Y. (2005). Designing babies: what the future holds. Reproductive BioMedicine Online, 10, 24-26. doi: 10.1016/s1472-6483(10)62200-6 